CLINICAL STUDY

\title{
The spectrum of phenotypes associated with mutations in steroidogenic factor 1 (SF-1, NR5A1, Ad4BP) includes severe penoscrotal hypospadias in $46, \mathrm{XY}$ males without adrenal insufficiency
}

\author{
Birgit Köhler, Lin Lin ${ }^{1}$, Inas Mazen ${ }^{2}$, Cigdem Cetindag, Heike Biebermann, Ilker Akkurt ${ }^{3}$, Rainer Rossi ${ }^{4}$, Olaf Hiort ${ }^{5}$, \\ Annette Grüters and John C Achermann ${ }^{1}$ \\ Department of Pediatric Endocrinology, University Children's Hospital, Charité, Humboldt University, Augustenburger Platz 1, 13353 Berlin, Germany, \\ ${ }^{1}$ Developmental Endocrinology Research Group, UCL Institute of Child Health, University College London, London, UK, ${ }^{2}$ Department of Clinical Genetics, \\ National Research Center, Cairo, Egypt, ${ }^{3}$ Children's Hospital Altona, Hamburg, Germany, ${ }^{4}$ Children's Hospital Neukölln, Berlin, Germany and ${ }^{5}$ Division of \\ Pediatric Endocrinology, Department of Pediatrics, University of Lübeck, Lübeck, Germany
}

(Correspondence should be addressed to B Köhler; Email: birgit.koehler@charite.de)

\begin{abstract}
Objective: Hypospadias is a frequent congenital anomaly but in most cases an underlying cause is not found. Steroidogenic factor 1 (SF-1, NR5A1, Ad4BP) is a key regulator of human sex development and an increasing number of SF-1 (NR5A1) mutations are reported in 46,XY disorders of sex development (DSD). We hypothesized that NR 5A1 mutations could be identified in boys with hypospadias.

Design and methods: Mutational analysis of NR5A1 in 60 individuals with varying degrees of hypospadias from the German DSD network.

Results: Heterozygous NR5A1 mutations were found in three out of 60 cases. These three individuals represented the most severe end of the spectrum studied as they presented with penoscrotal hypospadias, variable androgenization of the phallus and undescended testes (three out of 20 cases (15\%) with this phenotype). Testosterone was low in all three patients and inhibin B/anti-Müllerian hormone (AMH) were low in two patients. Two patients had a clear male gender assignment. Gender re-assignment to male occurred in the third case. Two patients harbored heterozygous nonsense mutations (p.Q107X/WT, p.E11X/WT). One patient had a heterozygous splice site mutation in intron 2 (c.103-3A/WT) predicted to disrupt the main DNA-binding motif. Functional studies of the nonsense mutants showed impaired transcriptional activation of an SF-1-responsive promoter (Cyp11a). To date, adrenal insufficiency has not occurred in any of the patients.

Conclusions: SF-1 (NR5A1) mutations should be considered in 46,XY individuals with severe (penoscrotal) hypospadias, especially if undescended testes, low testosterone, or low inhibin B/AMH levels are present. SF-1 mutations in milder forms of idiopathic hypospadias are unlikely to be common.
\end{abstract}

European Journal of Endocrinology $161237-242$

\section{Introduction}

Hypospadias is one of the most frequent congenital anomalies in boys, occurring with a frequency of approximately one in every 250 newborn males $(1,2)$. The clinical spectrum of this condition ranges from severe forms, where the urethra opens in the scrotum or penoscrotal junction, to milder forms, where the urethral opening is located on the penile midshaft or glans. Some cases of hypospadias are associated with specific syndromic features and, in some cases, underdevelopment of the phallus and/or undescended testes may be present.

Hypospadias results from a ventral fusion defect of the urethra during embryonic development, which occurs between 8 and 12 weeks gestation in humans (3). The first phase of elongation and patterning of the genital tubercle occurs in both sexes and is mainly controlled by developmental genes (e.g. SHH, HOXA13, HOXD13) and local growth factors (e.g. FGF8, FGF10, FGFR-IIIB, BMP7). The second phase of phallic growth occurs in males under the influence of androgen (dihydrotestosterone, DHT) action (4). In rare cases, a defect in one of these factors has been found to be associated with syndromic or nonsyndromic forms of hypospadias in humans (e.g. HOXA13, FGF8, FGFR2) (5, 6). Similarly, variable loss-of-function changes in the transcription factors, receptors, and enzyme pathways involved in Leydig cell development, androgen biosynthesis, and androgen action have also been found to be a cause of 
hypospadias in a few individuals (e.g. CXorf6, LHCGR, STAR, CYP11A1, HSD3B2, CYP17A1, POR, HSD17B3, SRD5A2, AR) (7-12). These patients often have associated micropenis and unilateral or bilateral cryptorchidism as androgens are implicated in phallic growth and the second stage of testis descent. Furthermore, mutations in the Wilms' tumor suppressor gene (WT1), a gene that plays a role in testis and kidney development, have been described in patients with hypospadias and kidney disease $(13,14)$.

Despite advances in our understanding of these developmental processes, the exact etiology of hypospadias remains unknown in most cases. It is quite possible that multifactorial influences are important, and environmental modulators of the androgen/estrogen pathway (e.g. pesticides) have been implicated in the potential population increase in this condition (15). However, it is plausible that other single gene disorders may result in hypospadias, either alone or as part of an oligogenic network. One key candidate gene known to be involved in testis development and steroidogenesis is NR5A1, which encodes the nuclear receptor steroidogenic factor 1 (SF-1, Ad4BP) (16). Mutations in NR5A1 are emerging as a relatively frequent cause of some forms of $46, \mathrm{XY}$ disorders of sex development (DSD; partial testicular dysgenesis, impaired androgen synthesis) and in most cases reported to date, the underandrogenization has been sufficiently severe to lead to a female gender assignment (17-19). Here, we investigate the frequency of NR $5 A 1$ mutations in a cohort of individuals with severe penile or penoscrotal hypospadias.

\section{Methods}

\section{Patients}

The cohort studied consisted of 60 46,XY DSD patients from the 'German Network of Disorders of Sex Development' who had presented at birth with variable degrees of hypospadias ranging from severe penile to penoscrotal forms. Twenty-four patients had penile hypospadias. Of these, 18 patients had descended testes and six patients had at least one undescended testis. Thirty-six patients had peno-scrotal hypospadias. Of these, 16 patients had descended testes and 20 patients had at least one undescended testis. Adrenal insufficiency, other endocrine disorders or syndromic features were not reported in any of these patients. Ethical review board approval was granted and informed consent was obtained from all parents according to institutional guidelines.

\section{Molecular analysis of NR5A1}

Genomic DNA was extracted from peripheral blood leukocytes using a Qiamp DNA blood kit (Qiagen). Direct sequencing of the six coding exons of NR5A1 (exons 2-7) was performed as described previously (18).

\section{Splice-site mutation}

Genscan splice prediction software (http://genes.mit. edu/GENSCAN.html) was used to assess the consequences of the splice site mutation detected.

\section{Transient gene expression assays}

Expression vectors containing the p.E11X or p.Q107X nonsense mutants were generated by site-directed mutagenesis (QuikChange, Stratagene, Amsterdam, The Netherlands) using wild-type (WT) pCMXSF-1 as a template. The entire coding sequence was confirmed by direct sequencing prior to functional analyses. Transient transfection studies were performed in 96-well plates using lipofectamine 2000 (Invitrogen) and a dual-luciferase reporter assay system (Promega). Studies were performed in tsa201 human embryonic kidney cells by transfecting empty, WT, or mutant SF-1 expression vectors (2 ng/well; p.G35E, p.E11X, p.Q107X,) with the SF-1-responsive minimal promoter of Cyp 11a linked to luciferase (100 ng/well). Cells were lysed $24 \mathrm{~h}$ following transfection and assayed for luciferase activity (Dual Luciferase Reporter Assay system, Promega; FLUOstar Optima, BMG Labtech, Aylesbury, UK), with standardization for Renilla co-expression. Results are shown as the mean \pm s.E.M. of three independent experiments, each performed in triplicate.

\section{Studies of SF-1 nuclear localization}

Mutant GFP-SF-1 constructs were generated by sitedirected mutagenesis in a pAcGFP-C1 vector (Clontech) to produce mutant fusion proteins with a GFP tag at the amino-terminus of SF-1. WT and mutant pAcGFPC1SF-1 expression vectors $(0.8 \mu \mathrm{g})$ were transfected into tsa 201 cells. After $24 \mathrm{~h}$, cells were fixed and nuclear counterstaining performed with Vectashield containing DAPI (Vector Laboratories, Peterborough, UK) (data not shown).

\section{Results}

\section{Cohort analysis}

SF-1 (NR5A1) mutations were found in 3 out of $60(5 \%)$ patients studied. An overview of these changes and clinical phenotypes is provided in Table 1. Of note, these changes were found only in patients with severe penoscrotal hypospadias and undescended testes ( 3 out of 20, 15\%). No SF-1 mutations were found in this cohort in those patients with penile hypospadias and/or bilaterally descended testes. 
Table 1 Clinical, biochemical, and genetic characteristics of the three patients with NR5A1 mutations in this series.

\begin{tabular}{|c|c|c|c|c|c|c|c|}
\hline Patient & Age & $\begin{array}{l}\text { External } \\
\text { genitalia }\end{array}$ & Testes $^{a}$ & Uterus $^{a}$ & $\begin{array}{l}\text { Endocrine data at } \\
\text { diagnosis }\end{array}$ & $\begin{array}{l}\text { Sex } \\
\text { assignment }\end{array}$ & Mutation \\
\hline 1 & At birth & $\begin{array}{l}\text { Normal phallus; peno- } \\
\text { scrotal hypospadias; } \\
\text { bilateral inguinal } \\
\text { gonads }\end{array}$ & Yes & No & $\begin{array}{l}\text { Age } 7 \text { days: testosterone } \\
0.4 \mathrm{ng} / \mathrm{ml} \mathrm{LH} 1.2 \mathrm{U} / \mathrm{l} \\
\text { FSH }<1 \mathrm{U} / \mathrm{l} \\
\text { Age } 4 \text { years: inhibin B } \\
63 \mathrm{pg} / \mathrm{ml} \text { AMH } 15 \mathrm{ng} / \mathrm{ml} \\
\text { (low) }\end{array}$ & $\widehat{0}$ & $\begin{array}{l}\text { p.Q107X/WT } \\
\text { (exon 4) }\end{array}$ \\
\hline 2 & At birth & $\begin{array}{l}\text { Phallus } 2.5 \mathrm{~cm} \\
(-2.5 \text { s.D.) with } \\
\text { minimal chordee; scro- } \\
\text { tal hypospadias; } \\
\text { bilateral inguinal } \\
\text { gonads }\end{array}$ & Yes & $\begin{array}{l}\text { No } \\
\quad \text { (vaginal rest) }\end{array}$ & $\begin{array}{l}\text { Age } 7 \text { days: } \mathrm{hCG} \text { stimu- } \\
\text { lation: testosterone } \\
0.4 \rightarrow 0.9 \mathrm{ng} / \mathrm{ml} \mathrm{LH} \\
0.65 \mathrm{U} / \mathrm{l}, \mathrm{FSH} 7.9 \mathrm{U} / \mathrm{l} \\
\text { Inhibin } \mathrm{B} 47 \mathrm{pg} / \mathrm{ml} \text { (low) }\end{array}$ & 0 & $\begin{array}{l}\text { c.103-3C > } \\
\text { A/WT (intron } \\
2 \text { splice } \\
\text { acceptor } \\
\text { site) }\end{array}$ \\
\hline 3 & 4 years & $\begin{array}{l}\text { Phallus } 2 \mathrm{~cm} \text { (-3.8 s.D.); } \\
\text { ( } 2.5 \mathrm{~cm} \text { after DHT); } \\
\text { penoscrotal hypospa- } \\
\text { dias; bilateral inguinal } \\
\text { gonads }\end{array}$ & Yes & No & $\begin{array}{l}\text { Age } 4 \text { years: hCG stimu- } \\
\text { lation: testosterone } \\
0.05 \rightarrow 0.58 \mathrm{ng} / \mathrm{ml}\end{array}$ & $q>0$ & $\begin{array}{c}\text { p.E11X/WT } \\
\text { (exon 2) }\end{array}$ \\
\hline
\end{tabular}

Normal range of: basal testosterone at 7 days $0.12-2.0 \mathrm{ng} / \mathrm{ml}, 6$ months to 7 years $<0.1-0.65 \mathrm{ng} / \mathrm{ml}$; LH at 7 days $0.1-1.0 \mathrm{U} / \mathrm{l} ; \mathrm{FSH}$ at $7 \mathrm{days} 0.3-4.0 \mathrm{U} /$; inhibin B at 0-1 months $68-630 \mathrm{pg} / \mathrm{ml}, 4-10$ years $50-258 \mathrm{pg} / \mathrm{ml}$; anti-Müllerian hormone at 4 years $45-85 \mathrm{ng} / \mathrm{ml}$ (conversion factors to SI units are: 3.47 for testosterone (nmol/l), 7.14 for $\mathrm{AMH}(\mathrm{pmol} / \mathrm{l})$ ). Cortisol, DHEAS, and 17-hydroxyprogesterone as markers of basal adrenal function were all normal where studied.

${ }^{\text {a } T e s t e s / u t e r u s ~ a s ~ v i s u a l i z e d ~ b y ~ u l t r a s o u n d ~ a n d / o r ~ l a p a r o s c o p y ~(p a t i e n t ~ 2) . ~}$

\section{Case histories}

All three patients were diagnosed with severe hypospadias and undescended inguinal testes at birth. Subject 1 had a normal penile length at birth whereas subjects 2 and 3 both had a small phallus (subject 2 , $2.5 \mathrm{~cm},-2.5$ SDS at birth; subject $3,2 \mathrm{~cm},-3.8$ SDS at 4 years; Table 1 ). Only patient 2 displayed a minimal chordee. In all the cases, there was a single opening at the base of phallus with no vaginal introitus. Complete scrotal midline fusion was seen in all patients, although the scrotum was slightly hypoplastic with decreased plication in patients 2 and 3. Endocrine evaluation at diagnosis showed low basal testosterone levels in all three patients and impaired testosterone response to human chorionic gonadotrophin (hCG) stimulation when tested (patients 2 and 3). Furthermore, patient 1 had low anti-Müllerian hormone (AMH) levels at 4 years of age and patient 2 had low inhibin $B$ and slightly elevated FSH at 7 days of age (Table 1). No Müllerian structures were found by ultrasound in patients 1 and 3 , whereas a uterine remnant was suspected by ultrasound in patient 2 , which was revealed to be a vaginal rest by genitography and laparoscopy. Bilateral inguinal gonads consistent with the testes were seen by ultrasound in all three patients (patient 1, $2 \mathrm{ml} / 2 \mathrm{ml}$ at 4 years; patient $2,1 \mathrm{ml} / 1 \mathrm{ml}$ at birth; patient $3,3 \mathrm{ml} / 3 \mathrm{ml}$ at 4 years). As testicular architecture appeared normal, no biopsies were performed. Male gender assignment was made in subjects 1 and 2 at birth and hypospadias repair and orchidopexy was undertaken. Patient 3 was born in a rural area of Egypt and presented to the National
Research Center of Cairo at the age of 4 years. At that time, a small phallus $(2 \mathrm{~cm})$, penoscrotal hypospadias and inguinal testes were seen. The karyotype was $46, \mathrm{XY}$, testosterone was low before and after hCG stimulation, and no uterus was present (Table 1). Until this point the patient had been raised as a girl but gender reassignment was considered based on the clinical features, investigations, and parental views. A trial of DHT cream (Andractim 2.5\%, applied to the phallus once daily at a dose of $\sim 5-10 \mathrm{mg}$ daily) resulted in an increase in phallic length from 2 to $2.5 \mathrm{~cm}$ and gender reassigment to male is currently in progress. Of note, basal cortisol, 17-hydroxyprogesterone and DHEAS were within normal ranges in patient 1 and 2 at diagnosis, and no symptoms or signs of adrenal insufficiency have emerged in any of the patients during follow up.

\section{SF-1 (NR5A1) mutations detected}

Patient 1 has a heterozygous $\mathrm{C}$ to $\mathrm{T}$ substitution in exon 4 (c.319 $\mathrm{C}>\mathrm{T}$ ) resulting in a change from glutamine to a stop codon at position 107 (p.Q107X/ WT) (Fig. 1A). Patient 2 has a heterozygous $\mathrm{C}$ to $\mathrm{A}$ substitution within the splice acceptor site of intron 2 (c.103-3C > A/WT; ctcccgcagGGCTTC > ctcccgaag GGCTTC). Patient 3 has a heterozygous $G$ to $T$ substitution in exon 2 (c.31G $>$ T) resulting in a change from glutamate to a stop codon at position 11 (p.E11X/WT). Analysis of DNA from 100 healthy control subjects (200 alleles) did not detect any of these novel changes by restriction analysis. 

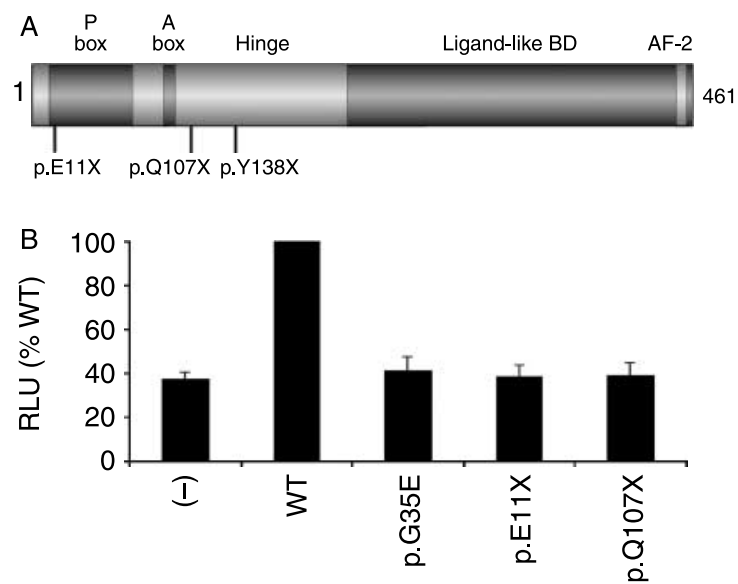

C
WT

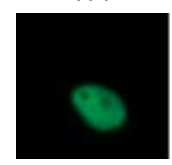

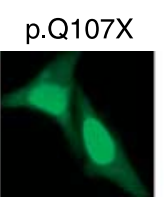

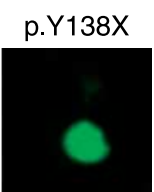

Figure 1 (A) Cartoon of the structure of SF-1 showing the position of the nonsense mutations reported here (p.E11X, p.Q107X) together with that of the previously reported p.Y138X change (18). (B) The p.E11X and p.Q107X mutants show impaired transcriptional activity in an assay using the minimal promoter of Cyp11a in tsa201 cells. The activity of the previously described p.G35E mutant is shown for comparison (19). Data represent the mean \pm S.E.M. of three independent experiments, each performed in triplicate. (-), empty vector; WT, wild-type; RLU, relative lights units. (C) Expression and cellular localization of WT and mutant GFP-SF-1 fusion proteins. WT GFP-SF-1 localizes in the nucleus with relative nucleolar exclusion. A truncated protein corresponding to the p.E11X nonsense mutant reported here is located throughout the cell, whilst low levels of cytoplasmic fusion protein are seen with p.Q107X. In contrast, the previously reported p.Y138X change is strongly localized to the nucleus with signal in the nucleolus too (18). These studies largely support reports that the nuclear localization signal of SF-1 requires codons $89-101$ with bipartite basic motifs at either end of this region being particularly important (33).

\section{Functional studies of SF-1 activity (p.E11X, p.Q107X)}

The two nonsense mutants studied (p.E11X, p.Q107X) showed markedly impaired transcriptional activity in an established assay of SF-1 function (Fig. 1B). Although these changes might be subject to nonsense mediateddecay, any translated p.E11X or p.Q107X protein would be predicted to lack of most of the functional domains of SF-1 (Fig. 1A) and have altered nuclear localization (Fig. 1C).

\section{Altered splicing (c.103-3C $>A)$}

Using Genscan splice prediction software, the c.103$3 \mathrm{C}>\mathrm{A}$ change is likely to affect splicing at the intron 2-exon 3 splice acceptor site. Potentially, an additional three amino acids (LPK) are inserted into the first zinc finger of the SF-1 protein. This insertion between codons 34 and 35 would disrupt the proximal ('P') box motif (ESCKG $>$ ESCKLPKG), the critical DNA binding region of SF-1.

\section{Discussion}

Steroidogenic factor 1 (NR5A1) is a transcription factor that plays a central role in gonadal and adrenal development. SF-1 also regulates the transcription of several enzymes involved in steroid/androgen biosynthesis. Although the initial search for SF-1 changes in humans focused on patients with combined gonadal and adrenal failure $(19,20)$, more recent case reports and series have shown that heterozygous NR5A1 (SF-1) mutations can be found relatively frequently in $46, \mathrm{XY}$ patients with severe underandrogenization, mild or partial gonadal dysgenesis, impaired androgen synthesis, and apparently normal adrenal function, or in 46,XX girls or women with ovarian insufficiency $(17,18,21-26)$. Thus, patients with SF1 mutations can present with a predominantly gonadal phenotype in humans (27). So far, most of the reported patients with severe underandrogenization have been raised as females.

A spectrum of phenotypes exists for most developmental endocrine conditions. As we have reported a SF-1 mutation (p.L437Q) in one patient (penoscrotal hypospadias, high scrotal testes) who was raised male, we hypothesized that loss-of-function mutations in SF-1 might also be found in 46,XY patients with hypospadias but without adrenal failure (17). Indeed, a milder loss of function change in SF-1 has been reported in association with micropenis and bilateral anorchia, and a nonsynonymous polymorphism in SF-1 may be associated with micropenis and undescended testes in population studies (28-30).

In the cohort of children with a range of nonsyndromic hypospadiac disorders described here, novel heterozygous SF-1 (NR5A1) mutations were found in $5 \%(3 / 60)$ of the entire group, and in 3/20 (15\%) of those with the most severe phenotype comprising severe penoscrotal hypospadias, small to normal phallus, inguinal testes and low testosterone levels. In patient 2 gonadal dysgenesis was present at birth as reflected by the low inhibin B, AMH and testosterone levels and the presence of a vaginal rest as a rudimentary Müllerian structure. In patient 1 , the decreased testosterone level at birth and the low amount of inhibin B in infancy may represent progressive gonadal dysgenesis. Patient 1 and 2 were raised as males from birth, whereas gender assignment in patient 3 was more challenging on account of a delayed presentation and the greater degree of genital ambiguity. Taken together, these cases show that heterozygous loss-of-function mutations in SF-1 (NR5A1) can be found in children with severe forms of hypospadias and that male sex of rearing of children with SF-1 mutations is possible, but SF-1 mutations are not 
found frequently in association with minor forms of hypospadias. To date, none of these patients have shown evidence of adrenal insufficiency, and it is uncertain if patients with SF-1 mutations are at risk of developing adrenal insufficiency in later life. Two patients with 46,XY DSD and adrenal failure have been reported, which may reflect more significant loss of SF-1 function in these cases $(19,20,31)$. Furthermore, it is unknown if DSD or hypospadiac patients with SF-1 mutations will have normal puberty and fertility or if there is an increased risk of testicular tumors due to gonadal dysgenesis. Subsequently, individuals with SF-1 mutations need long-term follow-up of adrenal and hypothalamic-pituitary-gonadal function and regular screening for gonadal tumors. In some individuals, sex assignment is challenging and long-term studies of gender identity and psychosexual functioning are needed. Thus, defining NR5A1 (SF-1) mutations of this group of individuals with severe hypospadias may have important implications in their later life, although further research is needed before specific guidelines or recommendations for genetic screening can be made.

In addition to the clinical implications of these findings, the identification of these three novel NR5A1 changes provides some insight into the biological function of SF-1. RNA containing the c.31G $>$ T (p.E11X) or c.319 C>T (p.Q107X) changes may be subject to nonsense mediated decay as well as loss of key functional domains in any translated protein (32). However, these naturally occurring changes, taken together with the previously reported p.Y138X mutation, support the hypothesis that the nuclear localization signal of SF-1 requires integrity of a bipartite basic motif around codons 89-101 in the distal DNA-binding and proximal hinge regions (Fig. 1C) $(18,33)$. Thus, the p.E11X mutant protein is located throughout the cell, whereas the p.Q107X protein is largely nuclear and the p.Y138X protein exclusively so. In contrast, the c.103-3C $>\mathrm{A}$ splice acceptor site change is predicted to generate a novel translated protein with insertion of three amino acids into the P-box (proximal) of the DNA-binding domain. This P-box motif is crucial for major groove binding and for dictating target gene specificity by nuclear receptors (34). However, the effects of splice site changes are often not complete and some normal protein is produced, which may contribute to the milder phenotype seen in this patient compared with the previously described individual with a p.G35E missense mutation in the P-box motif (19). It is also likely that modifier genes or epigenetic or environmental factors can influence individual phenotypes on top of a background of SF-1 haploinsufficiency.

\section{Declaration of interest}

There is no conflict of interest that could be perceived as prejudicing the impartiality of the research reported.

\section{Funding}

We are grateful to Ron Evans, Meera Ramayya, Masafumi Ito, and Larry Jameson for plasmids. This work was undertaken in part at Great Ormond Street Hospital for Children NHS Trust/UCL Institute of Child Health, which receives a proportion of funding from the Department of Health's NIHR Biomedical Research Centres' funding scheme. J C A holds a Wellcome Trust Senior Research Fellowship in Clinical Science (079666). B K holds a grant of the BMBF Network of Disorders of Sex Development (01GM0628).

\section{References}

1 Dolk H, Vrijheid M, Scott JE, Addor MC, Botting B, de Vigan C, de Walle H, Garne E, Loane M, Pierini A, Garcia-Minaur S, Physick N, Tenconi R, Wiesel A, Calzolari E \& Stone D. Toward the effective surveillance of hypospadias. Environmental Health Perspectives 2004112 398-402.

2 Paulozzi LJ. International trends in rates of hypospadias and cryptorchidism. Environmental Health Perspectives $1999 \mathbf{1 0 7}$ 297-302.

3 Goto M, Piper Hanley K, Marcos J, Wood PJ, Wright S, Postle AD, Cameron IT, Mason JI, Wilson DI \& Hanley NA. In humans, early cortisol biosynthesis provides a mechanism to safeguard female sexual development. Journal of Clinical Investigation $2006 \mathbf{1 1 6}$ 953-960.

4 Wilhelm D \& Koopman P. The makings of maleness: towards an integrated view of male sexual development. Nature Reviews. Genetics 20067 620-631.

5 Mortlock DP \& Innis JW. Mutation of HOXA13 in hand-foot-genital syndrome. Nature Genetics 199715 179-180.

6 Beleza-Meireles A, Lundberg F, Lagerstedt K, Zhou X, Omrani D, Frisen L \& Nordenskjold A. FGFR2, FGF8, FGF10 and BMP7 as candidate genes for hypospadias. European Journal of Human Genetics 200715 405-410.

7 Fukami M, Wada Y, Miyabayashi K, Nishino I, Hasegawa T, Nordenskjold A, Camerino G, Kretz C, Buj-Bello A, Laporte J, Yamada G, Morohashi K \& Ogata T. CXorf6 is a causative gene for hypospadias. Nature Genetics 200638 1369-1371.

8 Huhtaniemi I \& Alevizaki M. Gonadotrophin resistance. Best Practice and Research. Clinical Endocrinology and Metabolism 2006 20 561-576.

9 Simard J, Moisan AM \& Morel Y. Congenital adrenal hyperplasia due to 3beta-hydroxysteroid dehydrogenase/Delta(5)-Delta(4) isomerase deficiency. Seminars in Reproductive Medicine 200220 255-276.

10 Auchus RJ. The genetics, pathophysiology, and management of human deficiencies of P450c17. Endocrinology and Metabolism Clinics of North America 200130 101-119.

11 Lee YS, Kirk JM, Stanhope RG, Johnston DI, Harland S, Auchus RJ, Andersson S \& Hughes IA. Phenotypic variability in 17betahydroxysteroid dehydrogenase-3 deficiency and diagnostic pitfalls. Clinical Endocrinology 200767 20-28.

12 Boehmer AL, Nijman RJ, Lammers BA, de Coninck SJ, Van Hemel JO, Themmen AP, Mureau MA, de Jong FH, Brinkmann AO, Niermeijer MF \& Drop SL. Etiological studies of severe or familial hypospadias. Journal of Urology $2001 \mathbf{1 6 5}$ 1246-1254.

13 Kohler B, Schumacher V, Schulte-Overberg U, Biewald W, Lennert T, l'Allemand D, Royer-Pokora B \& Gruters A. Bilateral Wilms tumor in a boy with severe hypospadias and cryptochidism due to a heterozygous mutation in the WT1 gene. Pediatric Research $199945187-190$.

14 Kohler B, Delezoide AL, Boizet-Bonhoure B, McPhaul MJ, Sultan C \& Lumbroso S. Coexpression of Wilms' tumor suppressor 1 (WT1) and androgen receptor (AR) in the genital tract of human male embryos and regulation of AR promoter activity by WT1. Journal of Molecular Endocrinology 200738 547-554. 
15 Wang MH \& Baskin LS. Endocrine disruptors, genital development and hypospadias. Journal of Andrology 200829 499-505.

16 de-Souza BF, Lin L \& Achermann JC. Steroidogenic factor-1 (SF-1) and its relevance to pediatric endocrinology. Pediatric Endocrinology Reviews 20063 359-364.

17 Lin L, Philibert P, Ferraz-de-Souza B, Kelberman D, Homfray T, Albanese A, Molini V, Sebire NJ, Einaudi S, Conway GS, Hughes IA, Jameson JL, Sultan C, Dattani MT \& Achermann JC. Heterozygous missense mutations in steroidogenic factor 1 (SF1/Ad4BP, NR5A1) are associated with 46,XY disorders of sex development with normal adrenal function. Journal of Clinical Endocrinology and Metabolism 200792 991-999.

18 Kohler B, Lin L, Ferraz-de-Souza B, Wieacker P, Heidemann P, Schroder V, Biebermann H, Schnabel D, Gruters A \& Achermann JC. Five novel mutations in steroidogenic factor 1 (SF1, NR5A1) in 46,XY patients with severe underandrogenization but without adrenal insufficiency. Human Mutation 200829 59-64.

19 Achermann JC, Ito M, Ito M, Hindmarsh PC \& Jameson JL. A mutation in the gene encoding steroidogenic factor- 1 causes XY sex reversal and adrenal failure in humans. Nature Genetics 1999 22 125-126.

20 Achermann JC, Ozisik G, Ito M, Orun UA, Harmanci K, Gurakan B \& Jameson JL. Gonadal determination and adrenal development are regulated by the orphan nuclear receptor steroidogenic factor1, in a dose-dependent manner. Journal of Clinical Endocrinology and Metabolism 200287 1829-1833.

21 Reuter AL, Goji K, Bingham NC, Matsuo M \& Parker KL. A novel mutation in the accessory DNA-binding domain of human steroidogenic factor 1 causes XY gonadal dysgenesis without adrenal insufficiency. European Journal of Endocrinology 2007157 233-238.

22 Coutant R, Mallet D, Lahlou N, Bouhours-Nouet N, Guichet A, Coupris L, Croue A \& Morel Y. Heterozygous mutation of steroidogenic factor- 1 in $46, \mathrm{XY}$ subjects may mimic partial androgen insensitivity syndrome. Journal of Clinical Endocrinology and Metabolism 200792 2868-2873.

23 Mallet D, Bretones P, Michel-Calemard L, Dijoud F, David M \& Morel Y. Gonadal dysgenesis without adrenal insufficiency in a 46, $\mathrm{XY}$ patient heterozygous for the nonsense C16X mutation: a case of SF1 haploinsufficiency. Journal of Clinical Endocrinology and Metabolism 200489 4829-4832.

24 Hasegawa T, Fukami M, Sato N, Katsumata N, Sasaki G, Fukutani K, Morohashi K \& Ogata T. Testicular dysgenesis without adrenal insufficiency in a $46, \mathrm{XY}$ patient with a heterozygous inactive mutation of steroidogenic factor-1. Journal of Clinical Endocrinology and Metabolism 200489 5930-5935.

25 Correa RV, Domenice S, Bingham NC, Billerbeck AE, Rainey WE, Parker KL \& Mendonca BB. A microdeletion in the ligand binding domain of human steroidogenic factor 1 causes XY sex reversal without adrenal insufficiency. Journal of Clinical Endocrinology and Metabolism 200489 1767-1772.

26 Lourenco D, Brauner R, Lin L, De Perdigo A, Weryha G, Muresan M, Boudjenah R, Guerra-Junior G, Maciel-Guerra AT, Achermann JC, McElreavey $\mathrm{K} \&$ Bashamboo A. Mutations in NR5A1 associated with ovarian insufficiency. New England Journal of Medicine 2009360 1200-1210.

27 Jameson JL. Of mice and men: the tale of steroidogenic factor-1. Journal of Clinical Endocrinology and Metabolism 200489 5927-5929.

28 Philibert P, Zenaty D, Lin L, Soskin S, Audran F, Leger J, Achermann JC \& Sultan C. Mutational analysis of steroidogenic factor 1 (NR5a1) in 24 boys with bilateral anorchia: a French collaborative study. Human Reproduction 200722 3255-3261.

29 Wada Y, Okada M, Hasegawa T \& Ogata T. Association of severe micropenis with Gly146Ala polymorphism in the gene for steroidogenic factor-1. Endocrine Journal 200552 445-448.

30 Wada Y, Okada M, Fukami M, Sasagawa I \& Ogata T. Association of cryptorchidism with Gly146Ala polymorphism in the gene for steroidogenic factor-1. Fertility and Sterility $2006 \mathbf{8 5} 787-790$.

31 Lin L \& Achermann JC. Steroidogenic factor-1 (SF-1, Ad4BP, NR5A1) and disorders of testis development. Sexual Development 20082 200-209.

32 Maquat LE. Nonsense-mediated mRNA decay: splicing, translation and mRNP dynamics. Nature Reviews. Molecular Cell Biology 2004 5 89-99.

33 Li LA, Chiang EF, Chen JC, Hsu NC, Chen YJ \& Chung BC. Function of steroidogenic factor 1 domains in nuclear localization, transactivation, and interaction with transcription factor TFIIB and c-Jun. Molecular Endocrinology 199913 1588-1598.

34 Umesono K \& Evans RM. Determinants of target gene specificity for steroid/thyroid hormone receptors. Cell 198957 1139-1146.

Received 10 March 2009

Accepted 7 April 2009 